\title{
A NEW POTENTIAL BIOMARKER IN EARLY DIAGNOSIS OF FIREFIGHTER LUNG FUNCTION IMPAIRMENT: DYNAMIC THIOL/DISULPHIDE HOMEOSTASIS
}

\author{
Meşide Gündüzöz' ${ }^{1}$, Servet Birgin İitaş², Lütfiye Tutkun ${ }^{3}$, Murat Büyükşekerci ${ }^{4}$, Sultan Pınar Çetintepe ${ }^{5}$, Ceylan \\ Bal $^{6}$, Murat Alışık', Serpil Erdoğan ${ }^{7}$, Hınç Yılmaz ${ }^{8}$, Özcan Erel ${ }^{5}$ \\ ${ }^{1}$ Department of Family Medicine, Occupational Diseases Hospital, Ankara, Turkey \\ ${ }^{2}$ Council of Forensic Medicine, Branch Office of Ankara, Ankara, Turkey \\ ${ }^{3}$ Department of Medical Biochemistry, Bozok University, Faculty of Medicine, Yozgat, Turkey \\ ${ }^{4}$ Department of Pharmacology, Occupational Diseases Hospital, Ankara, Turkey \\ ${ }^{5}$ Department of Internal Medicine, Hacettepe University, Ankara, Turkey \\ ${ }^{6}$ Department of Biochemistry, Yldırım Beyazıt University, Ankara, Turkey \\ 'Department of Biochemistry, Atatürk Educational and Research Hospital, Ankara, Turkey \\ ${ }^{8}$ Department of Public Health, Yıldırım Beyazıt University Faculty of Medicine, Ankara, Turkey
}

\section{SUMMARY}

Objectives: The aim of this study was to investigate the associations between urinary arsenic, oxidative stress, assessed by thiol/disulphide homeostasis, and lung diseases in firefighters.

Methods: The study conducted among the municipality-based male firefighters $(n=100)$ who were admitted to occupational diseases clinic for periodic medical examination. The control group consisted of non-exposed male office workers $(n=50)$. Urinary arsenic levels, thiol/disulphide homeostasis parameters of participants were determined. Also, lung diseases were assessed by chest X-ray and pulmonary function tests.

Results: The mean age and work year did not differ in the study and control group. The median urinary arsenic concentration of firefighters was significantly higher than in the control group: $15.65(2.5-246) \mu \mathrm{g} / \mathrm{L}$ and $3(0.10-6) \mu \mathrm{g} / \mathrm{L}$, respectively $(\mathrm{p}<0.001)$. The parameters of pulmonary function tests (PFT) FVC (\%), FEV1 (\%), FEV1/FVC ratio and FEF 25-75 (\%) were all significantly lower in firefighters compared to controls. A significant increase in mean serum disulphide concentration (17.10 $\pm 8.31 \mu \mathrm{mol} / \mathrm{L} \mathrm{vs.} 7.48 \pm 5.91)$ (Fig. 1) and disulphide/native thiol \% ratio: 3.63 $(0.53-11.43)$ vs. $1.51(0.03-7.65)(p<0.001)$ were found between exposed group and controls. The Spearman's correlation analysis revealed a positive correlation between urinary arsenic and disulphide $(r=0.422, p<0.001)$, disulphide/native thiol \% ratio $(r=0.409, p<0.001)$. Nevertheless, urinary arsenic correlated negatively with all PFT parameters including FVC (\%), FEV1 (\%), FEV1/FVC and FEF 25-75 (\%) $(p<0.001)$.

Conclusion: We showed the arsenic-induced oxidative stress in firefighters with impairments of several lung functions determined by thiol/ disulphide homeostasis using a novel method.

Key words: firefighters, thiol/disulphide homeostasis, arsenic, respiratory function disorder, X-ray abnormality

Address for correspondence: Servet Birgin Iritaş, Council of Forensic Medicine, Branch Office of Ankara, Ankara, Turkey. E-mail: sbiritas@ gmail.com

https://doi.org/10.21101/cejph.a4972

\section{INTRODUCTION}

Firefighting is one of the high-risk professions around the world. While acute injury in the line of duty is the commonest problem firefighters encounter, little is known about the latent chronic illnesses which may occur as a result of firefighting (1). The potential for firefighters to contract acute and/or chronic respiratory health conditions associated with exposures during firefighting activities has long been recognized. Due to their potential for respiratory toxicity, specific exposures of concern for firefighters include: asphyxiates (such as carbon monoxide, carbon dioxide, hydrogen cyanide, and hydrogen sulphide), irritants (such as ammonia, hydrogen chloride, particulates, nitrogen oxides, phenol and sulphur dioxide), allergens and carcinogens (such as asbestos, benzene, styrene, polycyclic aromatic hydrocarbons) (2). Smokes may be also composed of distinctive trace and heavy metals such as lead, boron, cadmium, selenium, arsenic, antimony, and molybdenum (3). New data show that inorganic arsenic may also lead to non-malignant respiratory system malfunctioning (4). Arsenic amends multiple cellular pathways consisting of expression of growth factors, suppression of cell cycle checkpoint proteins, development of and resistance 
to apoptosis, inhibition of DNA repair and changes in DNA methylation, decline in immune surveillance, and enhanced oxidative stress through the upsetting of pro/antioxidant balance. These changes play outstanding roles in disease manifestation, such as carcinogenicity, genotoxicity, diabetes, cardiovascular and nervous systems disorders. Inflection of cellular thiols for protection against reactive oxygen species has over time been used as a therapeutic strategy against arsenic (5).

Wood smoke particles include free radicals and other substances which create reactive oxygen species (ROS) within the cells. These substances include metals, polycyclic aromatic hydrocarbons (PAHs), and other organic combinations (6). Woodfire generates smokes with plentiful particles in the inhalable range $(<100 \mu \mathrm{m})$ and include both carbon radicals and precursors. The latter is able to respond with $\mathrm{H}_{2} \mathrm{O}_{2}$ after exposure to cells and produce the highly reactive hydroxyl radical $(\mathrm{OH})$ from a Fenton-like reaction.

In oxidative stress, thiols are oxidized to the disulphide and with reduction of these thiol-disulphide bonds, thiols are formed again. Thiol-disulphide homeostasis is provided with this dynamic circle. A deformity in this homeostasis causes a variety of disorders, being that the thiol/disulphide ratio plays critical roles in antioxidant protection, detoxification, signal transduction, regulation of enzymatic activity, apoptosis, and cellular signaling mechanisms (7).

Due to the high risk of the obstructive lung disease among firefighters, it is important that functional respiratory abnormalities should be recognized early. To avoid further exposures, appropriate measures must be used. Spirometry is an important tool applied for developing pneumotachographs, which are helpful in diagnosing conditions such as asthma, pulmonary fibrosis, cystic fibrosis, and chronic obstructive pulmonary disease (COPD) (8).

A considerable amount of literature has been published on the effect of wood smoke in firefighters but little is known about the relationship between urinary arsenic, oxidative stress and pulmonary function in firefighters. In this study, we observed the health status of respiratory system among firefighters and its relation to the oxidative stress they were exposed to. Toward that aim, we collected firefighters' data from medical files including spirometry and chest x-ray results. Furthermore, their blood samples were taken to measure thiol/disulphide homeostasis by using a novel method described recently (9).

\section{MATERIALS AND METHODS}

\section{Study Population}

The study was conducted among the municipality-based male firefighters $(\mathrm{n}=100)$ who were admitted to occupational diseases clinic for periodic medical examination and subjects working as officers were recruited as the control group $(n=50)$. The subjects suffering from acute and chronic diseases e.g. hypertension, diabetes mellitus, cardiovascular diseases, infectious diseases like tuberculosis, arthritis, malignancy and those taking vitamin supplements, antioxidants were excluded from the study. The study was approved by the local ethical committee and informed consent was obtained from all patients.

\section{Chest Radiographs and Spirometry Measurement}

Serum samples were taken at the end of the shift week. PA chest X-rays were evaluated by a chest disease specialist. A standard spirometry measurement was done with a dry-seal spirometer (Zan 100, nSpire Health Inc., Oberthulba, Germany). Pulmonary function tests were interpreted in accordance with the American Thoracic Society standards (10). Pulmonary function data included FVC percent predicted, FEV1 percent predicted, FEV1/ FVC actual, FEF $25-75$ percent predicted. A restrictive pattern was defined as $\mathrm{FVC}<80 \%$ predicted and a normal or high $\mathrm{FEV} 1 /$ FVC ratio. An obstructive pattern was defined as FEV1 $<80 \%$ predicted and FEV1/FVC ratio $<0.75$. Small airways obstruction was defined as a forced expiratory flow at $25-75 \%$ predicted value (FEF $25-75 \%$ ) $<65 \%$.

\section{Measurement of Thiol/Disulphide Homeostasis Pa- rameters}

Serum samples were taken at the end of the shift week to $16 \times 100 \mathrm{~mm}$ tubes with red caps containing no gel (BD Vacutainer). Serum samples were separated by centrifugation at 1,500 $\mathrm{g}$ for $10 \mathrm{~min}$ and stored at $-80^{\circ} \mathrm{C}$ until the analysis time. For serum thiol/disulphide homeostasis measurement, we used the spectrophotometric method described by Erel et al. (9). Dynamic disulphide bonds (SS) in the sample were reduced to functional thiol groups $(\mathrm{SH})$ by $\mathrm{NaBH} 4$. The unused $\mathrm{NaBH} 4$ remnants are completely removed by formaldehyde. Thus, this prevents the extra reduction of DTNB and further reduction of the formed disulphide bond, which are produced after the DTNB reaction. All thiol groups, including reduced and native thiol groups were determined after the reaction with 5,5-dithiobis(2-nitrobenzoic) acid (DTNB). Half of the difference between the total thiols and the native thiols was recorded as the dynamic disulphide amount. After the native thiols ( $\mathrm{SH}$ ) and total thiols were determined, the amount of disulphide (SS), disulphide/total thiol percent ratio $(\mathrm{SS} / \mathrm{SH}+\mathrm{SS})$, disulphide/native thiol percent ratio $(\mathrm{SS} / \mathrm{SH})$, and native thiol/total thiol percent ratio $(\mathrm{SH} / \mathrm{SH}+\mathrm{SS})$ were calculated.

\section{Urine Arsenic Measurement}

Arsenic levels were determined in morning spot urine samples using Inductively Coupled Plasma Mass Spectrometry (ICP-MS) (Agilent 7700 series, Tokyo, Japan). Urine samples were collected in sterile plastic pots and then diluted 1 in 10 with $5 \%$ nitric acid solution. Standard solution of arsenic was prepared by the dilution of certified standard solutions (High Purity Standards, Charleston, SC, USA). Two levels quality control materials were used (Seronorm, Billingstad, Norway). The arsenic calibration curve ranged from 0 to $100 \mu \mathrm{g} / \mathrm{L}$.

\section{Statistical Analyses}

Statistical analysis of the data was interpreted by using SPSS (Version 18.0) (SPSS Inc, Chicago, IL, USA). Coherence to normal distribution analysis was made by using Shapiro-Wilk test. Values were presented as mean \pm SD or, in case of non-normally distributed data, as median (minimum-maximum). The presence of a statistically significant difference among the groups in terms of continuous variables was examined with Student's t-test for 
parametric variables and Mann-Whitney U test for non-parametric variables. In the subgroup analysis of categories, the presence of a statistically significant difference among the groups was determined by Kruskal-Wallis test with Bonferroni correction when parameters are not normally distributed or with one-way ANOVA post-Hoc Bonferroni test when parameters are normally distributed. Correlation analyses were done using Spearman's correlation test. All results were accepted as statistically significant at $\mathrm{p}<0.05$.

\section{RESULTS}

Demographic and clinical characteristics of participating exposed firefighters and non-exposed control group are presented in Tables 1 and 2. The two groups were similar by means of age and work years. They were all male, non-smokers and white, nonHispanic. Median urinary arsenic concentration of firefighters was significantly higher than in the control group: $15.65(2.5-246) \mu \mathrm{g}$ /L and $3(0.10-6) \mu \mathrm{g} / \mathrm{L}$, respectively $(\mathrm{p}<0.001)$. The parameters of pulmonary function tests FVC (\%), FEV1 (\%), FEV1/FVC ratio and FEF 25-75 (\%), were all significantly lower in firefighters compared to controls. A significant increase in mean serum disulphide concentration $(17.10 \pm 8.31 \mu \mathrm{mol} / \mathrm{L}$ vs. $7.48 \pm 5.91)$ (Fig. 1) and disulphide/native thiol \% ratio: $3.63(0.53-11.43)$ vs. 1.51 $(0.03-7.65)(p<0.001)$ were found between exposed group and controls. The Sperman's correlation analysis revealed a positive correlation between urinary arsenic and disulphide $(\mathrm{r}=0.422$, $\mathrm{p}<0.001)$, disulphide/native thiol $\%$ ratio $(\mathrm{p}<0.001, \mathrm{r}=0.409)$. Nevertheless, urinary arsenic correlated negatively with all PFT parameters including FVC (\%), FEV1 (\%), FEV1/FVC and FEF 25-75 $(\%),(\mathrm{p}<0.001)$ (Table 3).

\section{DISCUSSION}

The major finding of this study was the shift in thiol/disulphide homeostasis in favour of disulphide in firefighters which indicates an oxidative stress status. The other important finding was that mean urinary arsenic concentration of firefighters was

Table 1. Demographics of exposed firefighter group and unexposed control group

\begin{tabular}{|l|c|c|c|}
\hline & $\begin{array}{c}\text { Firefighters } \\
(\mathbf{n}=100)\end{array}$ & $\begin{array}{c}\text { Control } \\
(\mathbf{n}=50)\end{array}$ & p-value \\
\hline Age (years) & $36.5 \pm 8.2$ & $37.2 \pm 8.5$ & NS \\
\hline Work time (years) & $15.8 \pm 6.2$ & $16.4 \pm 5.8$ & NS \\
\hline Male (\%) & 100 & 100 & NS \\
\hline Current smokers (\%) & 0 & 0 & NS \\
\hline White, non Hispanic & 100 & 100 & NS \\
\hline
\end{tabular}

Values are presented as mean \pm SD. NS - non significant

Table 2. Clinical characteristics of exposed firefighter group and unexposed control group

\begin{tabular}{|c|c|c|c|}
\hline & $\begin{array}{l}\text { Firefighters } \\
\quad(n=100)\end{array}$ & $\begin{array}{l}\text { Control } \\
(n=50)\end{array}$ & $p$-value* \\
\hline Arsenic ( $\mu \mathrm{g} / \mathrm{L})$ & $15.65(2.5-246)$ & $3(0.10-6)$ & $<0.001$ \\
\hline \multicolumn{4}{|l|}{ Pulmonary functions } \\
\hline FVC $(\%)$ & $93.03 \pm 14.94$ & $103.74 \pm 12.80$ & $<0.001$ \\
\hline FEV1 (\%) & $90.83 \pm 17.86$ & $105.68 \pm 11.58$ & $<0.001$ \\
\hline FEV1/FVC & $78.41 \pm 7.59$ & $105.86 \pm 6.86$ & $<0.001$ \\
\hline FEF 25-75 (\%) & $78.74 \pm 33.76$ & $101.06 \pm 21.75$ & $<0.001$ \\
\hline \multicolumn{4}{|l|}{ Oxidative stress parameters } \\
\hline Native thiol $(\mu \mathrm{mol} / \mathrm{L})$ & $434.70 \pm 47.01$ & $429.45 \pm 46.14$ & 0.517 \\
\hline Total thiol $(\mu \mathrm{mol} / \mathrm{L})$ & $457.85 \pm 43.86$ & $443.34 \pm 40.23$ & 0.052 \\
\hline Disulphid ( $\mu \mathrm{mol} / \mathrm{L})$ & $17.10 \pm 8.31$ & $7.48 \pm 5.91$ & $<0.001$ \\
\hline Disulphid/native thiol\% & $3.63(0.53-11.43)$ & $1.51(0.03-7.65)$ & $<0.001$ \\
\hline Disulphid/total thiol\% & $1.59(0.33-6.06)$ & $1.47(0.03-6.64)$ & 0.194 \\
\hline Abnormal chest X-ray $(\%)^{* *}$ & 51 & - & - \\
\hline Abnormal PFT $(\%)^{\star * *}$ & 38 & - & - \\
\hline $\begin{array}{l}\text { Abnormal chest X-ray + } \\
\text { Abnormal PFT (\%) }\end{array}$ & 11 & - & - \\
\hline
\end{tabular}

PFT - pulmonary function test

Values are presented as mean \pm SD or median (min-max); * $p<0.05$ is statistically significant; **one or more of these findings: mediastinal expansion, apical sequelae nodular opacity, interstitial opacity, blunting of costophrenic angle; ${ }^{* * *}$ presence of findings suggesting either small airway obstruction, obstructive lung disease, or restrictive lung disease. 
Table 3. Spearman's correlation coefficient (r) between urine arsenic and oxidative stress parameters and respiratory function test findings in exposed firefighter group

\begin{tabular}{|l|c|c|}
\hline \multirow{2}{*}{} & \multicolumn{2}{|c|}{ Arsenic } \\
\cline { 2 - 3 } & $\mathrm{p}$-value* & $r$ \\
\hline Native thiol & 0.568 & -0.047 \\
\hline Total thiol & 0.032 & 0.697 \\
\hline Disulphide & $<0.001$ & 0.422 \\
\hline Disulphide/native thiol\% & $<0.001$ & 0.409 \\
\hline Disulphide/total thiol\% & 0.076 & 0.145 \\
\hline FVC (\%) & $<0.001$ & -0.224 \\
\hline FEV1 (\%) & $<0.001$ & -0.291 \\
\hline FEV1/FVC & $<0.001$ & $-0,629$ \\
\hline FEF 25-75 (\%) & $<0.001$ & -0.282 \\
\hline
\end{tabular}

${ }^{*} p<0.05$ is statistically significant

significantly higher than controls. Furthermore, arsenic correlated directly with disulphide and disulphide/native thiol ratio and negatively with pulmonary function tests. Additionally, the significant decline in pulmonary function tests in exposed firefighters was found.

Chronic exposure to several xenobiotics induces oxidative stress in lungs $(11,12)$. This situation can arise due to either increased levels of oxidant radicals (11) or decreased levels of antioxidants (10). Limited data is available on the relationship between thiol/disulphide homeostasis and lung diseases (13, 14). Furthermore, our knowledge of abnormal thiol/disulphide homeostasis state is improving and now we know that abnormal thiol/disulphide homeostasis is linked to pathogenesis of a various diseases such as diabetes, cardiovascular disease, cancer, rheumatoid arthritis, chronic kidney disease, acquired immunodeficiency syndrome (AIDS), Parkinson's disease, Alzheimer's disease, Friedreich's ataxia (FRDA), multiple sclerosis and amyotrophic lateral sclerosis, and liver disorder (9). Thiols sustain oxidation by oxidants, then condense covalent disulphide bonds. In oxidative stress, the oxidation of cysteine residues form mixed disulphide and the formed disulphide bonds can be reduced to a thiol group. As expected significantly higher disulphide levels were observed in firefighters with abnormal respiratory function tests and chest $\mathrm{X}$-rays findings. The mean serum disulphide level was relatively

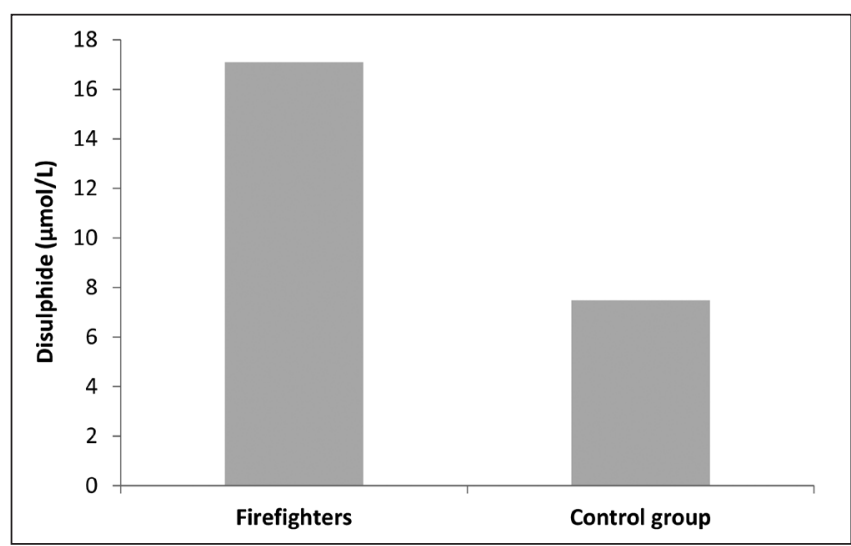

Fig. 1. Mean serum disulphide concentration. high in firefighters with abnormal pulmonary function test and chest X-ray (data not shown). It can be suggested that in the severe form of the illness that might correlate with chronic stage, the antioxidant system of the body partially defeats the oxidative state. In severe forms of the disease, worsening of the pulmonary functions may result in chronic hypoxia and oxidative stress may be expected. Likewise, Gaughan et al. showed the relation of wood smoke exposure and oxidative stress in firefighters expressed as changes in urinary 8-iso-prostaglandin F2 $\alpha$ (8-isoprostane) and 8-hydroxy-2'-deoxyguanosine (8-OHdG ) levels (15).

The fumes from wildfires have different particle sizes and chemical characteristics that can generate ROS. These particles can cause cellular respiratory burst, elevated generation of radical precursors, such as $\mathrm{H}_{2} \mathrm{O}_{2}$ and can also induce lipid peroxidation. The same radicals are likewise responsible for DNA damage. The most reactive particles were determined to be the ultrafine group, which can infiltrate furthest into the lung of an exposed firefighter (16). In this study the biomarker of exposure was limited to arsenic although the firefighters are exposed to a variety of toxicants. Since wood preservation has been made with copper chrome arsenic (CCA) based preservatives for many decades wood burn smoke and ashes may contain a substantial amount of arsenic (17). The mean urinary arsenic concentration of firefighters was 5-fold higher than controls. However, Wolfe et al. determined the urinary levels of arsenic in firefighters following a vegetative fire in Mexico in 2000 and they found no positive relation between urinary arsenic and exposure to smoke (18). In this study, the significant correlation between urinary arsenic level and FEV1, FVC, FEV1/FVC and FEF 25-75 (\%) values also supports the detrimental effect of arsenic exposure in wild firefighters' lung diseases.

The extent of pulmonary damage depends on the characteristics of exposed material, duration of exposure, and sensitivity of the individuals (19). Carbon monoxide, cyanide, low oxygen concentration, isocyanides, and nitrogen dioxide cause harm to the bronchi and alveoli leading to acute respiratory dysfunction (20). In addition, exposure to hydrochloric acid, nitrogen dioxide, sulphur dioxide, aldehydes, and ammonium cause inflammatory responses in the neutrophils that lead to elevated respiratory sensitivity, decreased respiratory function, harm to the respiratory conduction system in further cases causing chronic bronchitis, bronchiectasis, asthma, and pulmonary fibrosis (21).

Firefighters who were reported to be incompliant with using respiratory protection demonstrated an elevated risk of accelerated FEV1 decline. Serra et al. (22) examined lung function in 92 Sardinian firefighters with a control group of 51 police officers. They showed that firefighters had significantly lower FEV1 $(p<0.05)$, FEV1/FVC $(p<0.001)$, FEF75 $(p<0.05)$, FEF50 $(p<0.01), \operatorname{FEF} 25(p<0.001)$ and respiratory volume $(p<0.01)$ but no significant correlations were found between length of service, number of fires attended and respiratory measures. Similarly, Sparrow et al. (23) carried out lung function testing in 168 firefighters (79\% retention at 5 years) compared with 1,474 controls ( $78 \%$ retention at 5 years). The participants were taking part in a research study on aging. Lung function measurements revealed that FVC in firefighters was significantly lower than in the controls $(p<0.007)$ and FEV1 approached significance $(p=0.054)$. Jacquin et al. also claimed that firefighters are prone to develop respiratory impairments due to wood smoke exposure (24). 
Our study had several limitations. First, since the main biomarker of the study was arsenic, we could not determine other toxicants. Thus the contributing effect of other toxicants to oxidative stress could not be assessed. Second, it was not possible to adjust all factors that influence thiol status of participants such as diet, physical activity, and other unmeasured contributors.

As a result, we discovered that arsenic-induced oxidative stress plays an important role in the pathogenesis of lung disorders in firefighters. Thanks to the automated novel method, it was possible to assess the thiol/disulphide homeostasis simply, quickly and accurately. Further studies need to be carried out in order to understand the mechanisms underlying firefighters' lung diseases.

\section{Conflict of Interests}

None declared

\section{REFERENCES}

1. Daniels RD, Bertke S, Dahm MM, Yiin JH, Kubale TL, Hales TR, et al. Exposure-response relationships for select cancer and non-cancer health outcomes in a cohort of U.S. firefighters from San Francisco, Chicago and Philadelphia (1950-2009). Occup Environ Med. 2015 Oct;72(10):699706.

2. Fabian T, Borgerson JL, Kerber SI, Gandhi PD, Baxter CS, Ross CS, et al. Firefighter exposure to smoke particulates. Northbrook (IL): Underwriters Laboratories; 2010.

3. Fabian TZ, Borgerson JL, Gandhi PD, Baxter CS, Ross CS, Lockey JE. Characterization of firefighter smoke exposure. Fire Technol. 2014;50(4):993-1019.

4. Mazumder DN, Haque R, Ghosh N, De BK, Santra A, Chakraborti D, et al. Arsenic in drinking water and the prevalence of respiratory effects in West Bengal, India. Int J Epidemiol. 2000 Dec;29(6):1047-52.

5. Flora, SJ. Arsenic-induced oxidative stress and its reversibility. Free Radic Biol Med. 2011;51(2):257-81.

6. Danielsen PH, Møller P, Jensen KA, Sharma AK, Wallin H, Bossi R, et al. Oxidative stress, DNA damage, and inflammation induced by ambient air and wood smoke particulate matter in human A549 and THP-1 cell lines. Chem Res Toxicol. 2011 Feb 18;24(2):168-84.

7. Yilmaz ÖH, Bal C, Neşelioglu S, Büyükşekerci M, Gündüzöz M, Eren F, et al. Thiol/disulfide homeostasis in asphalt workers. Arch Environ Occup Health. 2016 Sep 2;71(5):268-72.

8. Schermer T, Malbon W, Newbury W, Holton C, Smith M, Morgan M, et al. Spirometry and impulse oscillometry (IOS) for detection of respiratory abnormalities in metropolitan firefighters. Respirology. 2010;15(6):97585 .
9. Erel O, Neselioglu S. A novel and automated assay for thiol/disulfide homeostasis. Clin Biochem. 2014;47(18):326-32.

10. Cantin AM, Fells GA, Hubbard RC, Crystal RG. Antioxidant macromolecules in the epithelial lining fluid of the normal human lower respiratory tract. J Clin Investig. 1990;86(3);962-71.

11. Repine JE, Bast A, Lankhorst I; Oxidative Stress Study Group. Oxidative stress in chronic obstructive pulmonary disease. Am J Respir Crit Care Med. 1997 Aug;156(2 Pt 1):341-57.

12. MacNee W. Oxidative stress and lung inflammation in airways disease. Eur J Pharmacol. 2001 Oct 19;429(1-3):195-207.

13. Beeh KM, Beier J, Koppenhoefer N, Buhl R. Increased glutathione disulfide and nitrosothiols in sputum supernatant of patients with stable COPD. Chest. 2004 Oct;126(4):1116-22.

14. Rietjens IM, Alink GM, Vos RM. The role of glutathione and changes in thiol homeostasis in cultured lung cells exposed to ozone. Toxicology. 1985;35(3):207-17.

15. Gaughan DM, Siegel PD, Hughes MD, Chang CY, Law BF, Campbell CR, et al. Arterial stiffness, oxidative stress, and smoke exposure in wildland firefighters. Am J Ind Med. 2014 Jul;57(7):748-56.

16. Leonard SS, Castranova V, Chen BT, Schwegler-Berry D, Hoover M, Piacitelli C, et al. Particle size-dependent radical generation from wildland fire smoke. Toxicology. 2007 Jul 1;236(1-2):103-13.

17. Fabian TZ, Borgerson JL, Gandhi PD, Baxter CS, Ross CS, Lockey JE, et al. Characterization of firefighter smoke exposure. Fire Technol. 2014;50(4):993-1019.

18. Wolfe MI, Mott JA, Voorhees RE, Sewell CM, Paschal D, Wood CM, et al. Assessment of urinary metals following exposure to a large vegetative fire, New Mexico, 2000. J Expo Anal Environ Epidemiol. 2004 Mar;14(2):120-8.

19. Jung TH. Respiratory diseases in firefighters and fire exposers. J Korean Med Assoc. 2008 Dec;51(12):1087-96.

20. Axford AT, McKerrow, CB, Jones AP, Le Quesne PM. Accidental exposure to isocyanate fumes in a group of firemen. Br J Ind Med. 1976 May;33(2):65-71.

21. Choi JH, Shin JH, Lee MY, Chung IS. Pulmonary function decline in firefighters and non-firefighters in South Korea. Ann Occup Environ Med. 2014 Apr 25;26:9. doi: 10.1186/2052-4374-26-9.

22. Serra A, Mocci F, Randaccio FS. Pulmonary function in Sardinian fire fighters. Am J Ind Med. 1996 Jul;30(1):78-82.

23. Sparrow D, Bossé R, Rosner B, Weiss ST. The effect of occupational exposure on pulmonary function: a longitudinal evaluation of fire fighters and nonfire fighters. Am Rev Respir Dis. 1982 Mar;125(3):319-22.

24. Jacquin L, Michelet P, Brocq FX, Houel JG, Truchet X, Auffray JP, et al. Short-term spirometric changes in wildland firefighters. Am J Ind Med. 2011;54(11):819-25.

Received November 7, 2016 Accepted in revised form April 16, 2018 